\title{
Sustainable Consumption AND the IMPORTANCE OF NEIGHBOURHOOD: A Central City/Suburb Comparison ${ }^{1}$
}

\author{
EMILY HudDart KenNEDy \\ NAOMI KROGMAN \\ HARVEY KRAHN
}

\begin{abstract}
This paper applies urban and environmental sociological theory to survey data on self-reported sustainable consumption practices, using a matched sample of central city and suburban residents in Edmonton, Alberta. We use cluster analysis to create an ordinal typology of four types of consumers, conduct an analysis of variance to characterize the resultant clusters, and perform logistic regression to predict the net effect of urban and neighbourhood context on sustainable consumption practices. We find that neighbourhood and environmental attitude are the strongest predictors of sustainable consumption practices. We conclude by arguing many sustainable activities are more difficult to incorporate into daily routine when residing in the suburban neighbourhood. While suburban residents may feel strongly that they should consume less, their geographic location appears to significantly constrain their ability to meaningfully reduce their own consumption. This urban Canadian case study has implications for middle class environmental practices in other North American urban and suburban settings.
\end{abstract}

Keywords: neighbourhood; sustainable consumption; compositionalism; determinism; political economy

Résumé. Le présent article applique la théorie sociologique urbaine et environnementale aux données d'un sondage sur des habitudes de consommation durables auto-déclarées, à partir d'un échantillonnage apparié de résidents du centre-ville et de la banlieue d'Edmonton (Alberta). L'article emploie l'analyse des grappes pour créer une typologie ordinale de quatre types de consommateurs, l'analyse de la variance pour caractériser les grappes résultantes, ainsi que la régression logistique pour prédire l'effet net du contexte de quartier et d'autres variables sur les habitudes de consommation durable. Le contexte de quartier et les attitudes environnementales sont les indicateurs les plus fiables des pratiques de consom-

1. All correspondence should be addressed to Emily Huddart Kennedy: huddartk@ualberta.ca. The authors acknowledge the financial support of the Social Sciences and Humanities Research Council of Canada (SSHRC), Grant no. 865-2008-18. 
mation. D'après nos constatations, il y a de nombreuses pratiques durables plus difficiles à incorporer au quotidien pour des banlieusards. Vivre en banlieue limite de façon significative la capacité de réduire appréciablement sa propre consommation, même si on est convaincu qu'on devrait consommer moins.

Mots clés: quartier; consommation durable; déterminisme; économie politique

\section{INTRODUCTION}

As international climate change treaties flounder (Berman and LeirenYoung 2011), the potential for local responses to environmental challenges has garnered increased attention (Fisket and Mamo 2007; Seyfang 2009). Knowledge of how physical and social communities function is now vital for the creation of pro-environmental outcomes. Despite theoretical advances on the topic of urban sustainability within environmental sociology (Lorr 2012), such theories insufficiently consider the impact of place, and specifically neighbourhood, on daily actions. Here, we explore the potential to apply urban and environmental sociological theory to the study of sustainable consumption practices.

In 2009, we interviewed families living throughout the city of Edmonton, Alberta, Canada, asking about their commitment to the environment and how they expressed that commitment in action. We established that informants living in the suburbs experience myriad challenges to living sustainably: the time required by commuting; the difficulty in forming neighbourhood social networks; and the distance to basic services. As a result of such barriers, a strong interest in the environment is not always followed by strong sustainable practices. As has been reported elsewhere, some central city residents report becoming "greener" by virtue of the location and structure of their neighbourhood, despite not necessarily identifying with the environmental movement (Kennedy 2011). We decided to explore this difference further, by administering a survey to a matched sample of residents of a suburban neighbourhood and of a central city neighbourhood in order to see whether and how selfreported sustainable daily practices differed between them. This paper presents the core findings of that survey. Our primary objective is to add to the scant literature contrasting household environmental behaviours in different urban contexts (Capek 2010) and to explore the applicability of urban sociology as a framework for understanding patterns of environmental behaviour at the neighbourhood level.

\section{Urban Sociological Perspectives on Place}

In addition to evidence from our interviews, there is a strong foundation in urban sociology leading us to expect that sustainable practices might 
differ by neighbourhood. Urban sociological perspectives have long credited neighbourhood with varying outcomes, including community engagement (Jacobs 1961; Sampson 2012), crime (Morenoff and Sampson 1997), and health (Kawachi and Berkman 2003). Sampson writes,

Whether it be crime, poverty, child health, protest, leadership networks, civic engagement, home foreclosures, teen births, altruism, mobility flows, collective efficacy, or immigration ... the city is ordered by a spatial logic ... and yields differences as much today as a century ago. (Sampson 2012:6)

However, the causal pathways from neighbourhood to such outcomes are not always clear.

Responding to those who argue place is less relevant in our globalized age (e.g., Friedman 2005; Giddens 1991), Sampson (2012) shows instead that spatially coordinated social differences exist and mediate structural and individual level processes. He identifies epistemological conflicts that have been debated in the urban literature. For example, complicating theories of neighbourhood effects is the issue of "selection bias" - do neighbourhoods attract certain types of residents who in turn establish daily rounds and socioeconomic outcomes? Or do collective, preexisting features of neighbourhoods - their sociodemographic, market-oriented, structural, or politico-economic characteristics - shape incoming residents, regardless of background? These questions about the dialectic between characteristics of neighbourhoods, who moves to them, and how they shape residents living in them are relevant to our analysis of associations among variables at different levels - household sustainable practices and demographic characteristics, individual attitudes, and neighbourhood characteristics.

The addition of sustainable practices to the neighbourhood effects literature is recent, yet likely to persist, as cities become the target of national and international climate change policies. Urban sociology has the potential to shed light on how environmental behaviour may vary according to the cultural and physical dimensions of neighbourhood contexts (May et al. 2005; Rudel 2009). In short, we argue that neighbourhood, long examined in analyses of race, power, mobility, and other sociological concerns (Gieryn 2000), also has the potential to influence levels of resource consumption (Capek 2010; Hodson and Marvin 2010). A brief overview of urban sociological perspectives, drawing on distinctions between compositionalism, environmental determinism, and political economy, will help frame the presentation and interpretation of our survey findings. 
Compositionalism is an agency-based account of urban life. From a compositionalist view, people are influenced by — and influence — those around them, and mimicking behaviour leads to unique, communitybased norms and efficacy. Evidence to date suggests that neighbourhoods do have normative standards and cultural rules, which residents use to structure their daily lives (Ross 2000). The core of the compositionalist perspective contends that the normative climate within which one is situated delimits the boundaries of which behaviours are acceptable and desirable (Brewster et al. 1993; Gans 1962; Ross 2000). One example of a compositional perspective on an environmentally related topic is Johnston et al.'s (2012:1092) treatment of ethical eating practices in two Toronto neighbourhoods. In describing their compositionalist construct, the "prototype," the authors state,

... understandings of ethical eating are significantly shaped by placespecific neighbourhood cultures that reflect and reproduce classed ways of eating. To conceptualize these cultures, we draw from the sociological study of culture and cognition, and develop the idea of a neighbourhood 'prototype'. The neighbourhood prototype reflects residents' perceptions of the typical eater in their neighbourhood, thereby incorporating people's perceptions of the material environment, as well as neighbourhood standards or ideals.... People compare themselves - both positively and negatively — to a neighbourhood prototype that sets a standard for 'normal' eating practices.

Compositionalism theoretically organizes what we could call the cultural dimensions of neighbourhood effects.

In contrast, determinism is highly structural, focusing on the characteristics of physical places, rather than individuals, groups, and cultures. For environmental determinists such as Park and Burgess, the market has a "natural" logic that governs urban life (Sampson 2012). With roots in the Chicago school, this perspective sees the social organization of urban dwellers as a function of ecological and economic factors (Sampson 2012). As Logan and Molotch (1987:5) explain, determinism proposes that "each type of land user ends up in the location to which the user is best adapted." For some Chicago school theorists, larger processes of urbanization, industrialization, and population growth were seen as generating social problems such as poverty (Wirth:1938). Though she was not a Chicago school theorist, Jane Jacobs' classic Death and Life of Great American Cities (1961) also viewed spatial patterns as inscribed by forces larger than the individual and as having a fundamental influence on the lives of its citizens.

The compositional hypothesis differs from the determinist perspective in that it argues that physical places, in isolation, have no effect on 
the lives of inhabitants independent of the demographic characteristics of residents and cultures of neighbourhoods. That is, certain types of people are drawn to live in certain types of places, and it is the characteristics of the individuals living there (e.g., race, class, socioeconomic status) - not their physical environment - that are associated with behaviours (Fischer 1976). Taking such a view, Gans (1962:172) criticized Jacobs' conclusion that "buildings, streets, and the planning principles on which they are based, shape human behavior," calling it a "physical fallacy" that ignores "social, cultural, and economic factors" (Gans 1962:172).

In their political economic approach to urban sociology, Logan and Molotch (1987:1) propose that the "fundamental attributes" of "land and buildings are the social, economic, and political contexts through which they are used and exchanged." They criticize the Chicago school for not adequately incorporating this broader context into their theories. Logan and Molotch call attention to the ways in which place can facilitate unique routines, and more crucially, how external actors can have undue influence on the lives of a city's residents. Through the workings of "the growth machine" that unites developers and local politicians, places (or neighbourhoods) may come to represent the interests of the powerful rather than the desires of local inhabitants. In particular, Logan and Molotch describe how exchange values (centred on profit) can ultimately affect use values such as "daily rounds" - those interactions between the physical amenities of an area (e.g., grocery stores) and the daily routines of a neighbourhood's residents. In turn, a daily round has broad implications for place attachment: "The specific meaning residents give to place is shaped by the ways they use the material and social resources at hand to make their daily round" (Logan and Molotch 1987:103).

Thus, Logan and Molotch (1987) integrate their conceptualization of power to the neighbourhood effects literature. By highlighting the structuring effect that neighbourhoods have on daily routines as well as the influence that residents and other actors have on neighbourhoods, they incorporate elements of both the determinist and the compositionalist perspectives. Absent from their work (not surprising, given it was published nearly three decades ago) is a consideration of the potential for daily rounds to differ in their environmental impact, incorporating (or not) certain sustainable, or environmental, practices. In this study, we describe how environmental practices differ by neighbourhood, recognizing that what we observed reflects some combination of external actors shaping neighbourhoods, individuals and families selecting neighbourhoods and, in turn, neighbourhoods shaping residents' behaviours. Our goal is not to test these perspectives, but rather to apply them to the issue of sustainable consumption, and consider the respective lessons that can be drawn from each line of inquiry. 


\section{Environmental Sociological Perspectives on Household Consumption}

Niemi and Hubacek (2007) conducted a qualitative study that distinguished among consumers with different daily consumption practices. The authors contrasted consumers according to their social relationships, consumption patterns, and levels to identify four types of consumers. Mainstream consumers "show no interest in reducing their material consumption and they seldom if ever buy any green products" (Niemi and Hubacek 2007:4). Material greens are those who buy green products but do not seek to reduce the overall amount they consume, or to adopt more stringent practices to reduce their environmental impact. Low-level consumers "live relatively simple lifestyles but they seldom or hardly ever choose an environmentally friendly option when making their purchasing decisions" (Niemi and Hubacek 2007:4). Finally, sustainable consumers aim to reduce their overall impact and buy environmentally friendly products. Johnston et al. (2012) devised a similar typology in a study of grocery shopping practices, using data from 47 semistructured interviews to identify consumer prototypes and argue that these are structured by neighbourhood of residence.

In the quantitative analysis we present below, we use Niemi and Hubacek's labels to describe the clusters of practices that emerged from our survey data. While Niemi and Hubacek's study does not presume any ordering of the consumer types, we posit that they form an ordinal ranking according to environmental impact, with sustainable consumers striving to have the lowest environmental impact, and mainstream consumers allocating the least amount of effort to reducing their impact. The intermediate categories, material greens and low-level consumers would, in theory, have intermediate levels of environmental impact. We expect the impact of material greens to be somewhat higher since the definition of this subgroup is that they choose to use consumption as a method of advancing environmental reform. Our goals in this paper are to determine how sustainable practices are clustered, in a behavioural (not a spatial) sense, and to ascertain any differences in the prevalence of each type of consumer type between a centrally located area and a comparable suburban neighbourhood.

\section{Methodology}

This paper is part of a larger research project that aims to identify attitudes and practices associated with reducing material consumption. The overall study, conducted in Edmonton, Alberta (Canada), takes a mixed methods approach and began with a theoretically driven qualitative sample that generated 26 interview transcripts as well as participant 
observation data. These data provided a deeper understanding of the barriers and supports to reducing consumption, identified specific behaviours practiced by those who strive to reduce their environmental impact, and highlighted the factors that motivate those who drastically reduce their material consumption. The findings from the qualitative phase led us to consider how domains of practice differ across households in urban and suburban areas. The qualitative data informed our quantitative study (presented here), first in measurement, helping us to develop a list of behavioural items, and second in sampling, leading us to consider the possibility that neighbourhood may have distinct effects on the engagement of sustainable daily practices.

We subsequently identified a matched pair of neighbourhoods for case studies of distinctly different urban contexts. In an attempt to control social class differences, we selected two neighbourhoods with similar average household income. Furthermore, our earlier interviews demonstrated the unique constraints on sustainable practices that result from different housing arrangements. For example, renting a home poses limitations on the energy retrofitting residents can do and living in an apartment constrains practices such as composting and growing one's own food. By controlling on these factors in our sampling (both neighbourhoods contain primarily detached dwellings owned by their residents) we are better able to isolate the exogenous influences associated with sustainable practices in central and suburban neighbourhoods.

\section{Study Context and Area}

Edmonton (the capital of the province of Alberta) is one of Canada's largest (by land area) and least densely populated cities although, in these respects, it is very similar to Alberta's other large city (Calgary) and numerous mid-sized, second-tier cities in the US (Table 1).

As a case study, Edmonton offers somewhat extreme examples of several wider trends including increasing levels of discretionary spending and use of personal vehicles. Edmonton is among the top three cities in Canada for household spending on consumer goods (Statistics Canada 2006). A recent report comparing major Canadian cities found that Edmonton residents (in 2005) were the most likely to have made all their trips on the reference day exclusively by car as either the driver or a passenger ( $75 \%$ and $77 \%$, respectively) (Turcotte 2008 ). As a northern city (roughly 500 kilometers from the US/Canada border), Edmonton's location is somewhat unique in North America. However, as already noted, with respect to population density (Table 1), presence of low-density suburbs (Baxandall and Ewen 2000), and persistent urban sprawl (Grant 2002), it is similar to quite a number of other North American cities. 
Table 1. Population Density of Edmonton, Calgary, and Comparably Sized US Cities (Source: City Mayors Statistics 2007)

\begin{tabular}{l|c|c|c}
\hline \multicolumn{1}{c}{ City } & Population & Land Area $(\mathrm{sq} . \mathrm{km})$ & Density $\left(\right.$ people $\left./ \mathrm{km}^{2}\right)$ \\
\hline Calgary & 879,000 & 702 & 1,250 \\
Memphis & 972,000 & 1,036 & 950 \\
Tucson & 720,000 & 755 & 950 \\
Edmonton & 782,000 & 850 & 900 \\
Jacksonville & 882,000 & 1,063 & 850 \\
Nashville & 750,000 & 1,116 & 650 \\
\hline
\end{tabular}

The two neighbourhoods sampled in our quantitative study are Millcreek and Terwillegar Towne. Millcreek, an older Edmonton neighbourhood, is within walking and cycling distance of the downtown and university districts. According to Turcotte's (2008a) definition (based on age of homes, distance to the city core, and density), Millcreek is a mediumdensity urban core neighbourhood. Terwillegar Towne, a recently built suburb, is located at the edge of the city, a 20-minute highway drive from downtown Edmonton. Terwillegar Towne is typical of low-density suburbia (Turcotte 2008a). Table 2 presents sociodemographic data comparing the two neighbourhoods, drawn from the Canadian Census and Elections Canada data.

Table 2. Demographic Profile of Millcreek and Terwillegar Towne (Source: City of Edmonton 2009 Municipal Census and Elections Canada)

\begin{tabular}{lcc}
\hline & Terwillegar Towne & Millcreek \\
\hline Number of households & 1349 & 637 \\
Residents living in single-detached homes (\%) & 80.6 & 81.9 \\
Residents who own their home (\%) & 93.0 & 86.3 \\
Average family size & 3.27 & 3.03 \\
Average household income (\$) & 135,468 & 113,105 \\
Low-income households (\%) & 6 & 10.5 \\
Median age of residents & $25-34$ & $35-44$ \\
Female residents (\%) & 53.8 & 49.5 \\
Immigrants (\%) & 20 & 21 \\
Adult residents with a university degree (\%) & 55 & 58 \\
\hline
\end{tabular}

\section{Millcreek}

Millcreek is located within three kilometers $(\mathrm{km})$ of the downtown area, the University of Alberta, and several other hubs of shops and services. It was established around the turn of the 20th century and is one of the older neighbourhoods in the city. The community lies on the edge of Millcreek Ravine, a $9 \mathrm{~km}$ long, forested, riparian park, and is characterized as high density by Statistics Canada (Turcotte 2008a). Grocery stores, bakeries, restaurants, and a variety of other shops and services are within walking distance from any home in the neighbourhood, and the area is well serviced by public transit and bike trails. Figure 1 is an aerial 


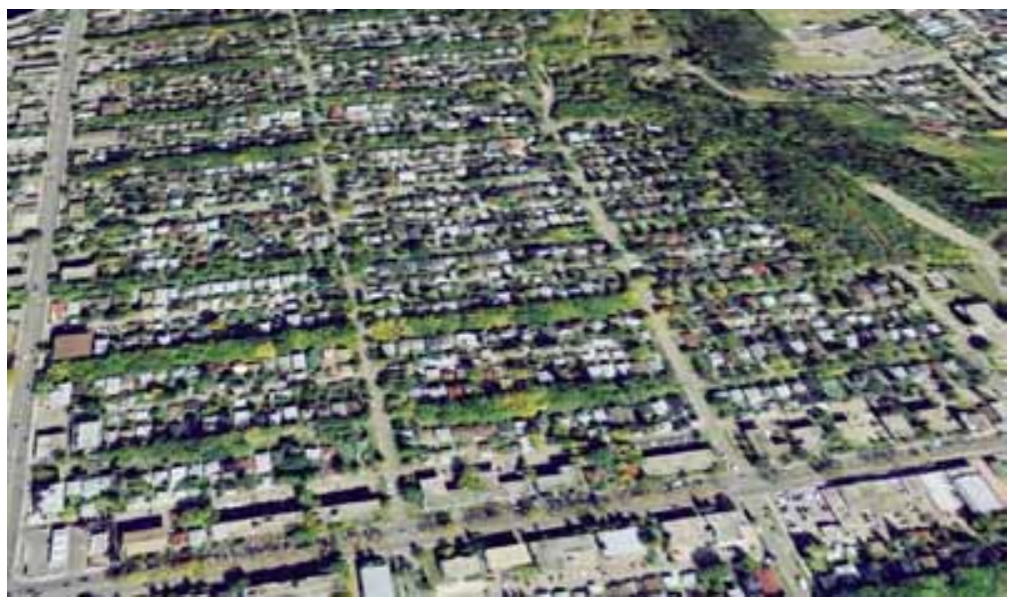

Figure 1. Millcreek Aerial Image (Source: Google Maps)

photograph of Millcreek, showing that the area is built on a grid system, is heavily treed, and lies adjacent to a riparian area. The neighbourhood also has a visual presence of residents who espouse an environmentally sustainable lifestyle, with a Net Zero home, a number of families who chose to home-school their children (in order to reduce their time spent driving and to facilitate living without a car), many households that do not own a vehicle, homes with front gardens growing native plants and vegetables, and an active Community League. As a participant from the qualitative phase of this study explains:

[Millcreek is] like a neighbourhood of excellence. If you found out tomorrow you couldn't drive your car anymore, many of us in this neighbourhood would just carry on doing our thing.... For the most part, people who loan me their car have said they admire how we live and they also know that their car sits unused $80 \%$ of the time. That's the kind of bartering that builds community here.

\section{Terwillegar Towne}

Built at the turn of the 21 st century, Terwillegar Towne is a low-density suburb located approximately $15 \mathrm{~km}$ from the city centre. A website created by the neighbourhood's developers clearly caters to the family buyer with traditional values and a concern for safety:

Edmonton's first neo-traditional community ... is a uniquely people-oriented place. Friendly, safe streets, neighborhood parks and open spaces, and traditional architecture combine to create a neighbourhood with a timeless appeal. At Terwillegar Towne 'the good old days' just got better."

2. http://www.terwillegartowne-community.com/frame main.html 
However, Terwillegar Towne is built in a suburban hinterland. Driving to and from the city centre for work requires at least an hour each day; there are no other feasible transportation options, and there are no shops and services within walking distance other than a "Macs" (chain) convenience store. Figure 2 is an aerial photograph of Terwillegar Towne that depicts the serpentine street layout (impeding the ability to efficiently walk to any local points of interest), the lack of tree cover (the suburban neighbourhood is too new to have any large trees), and two manmade riparian areas (e.g., bogs, ponds).

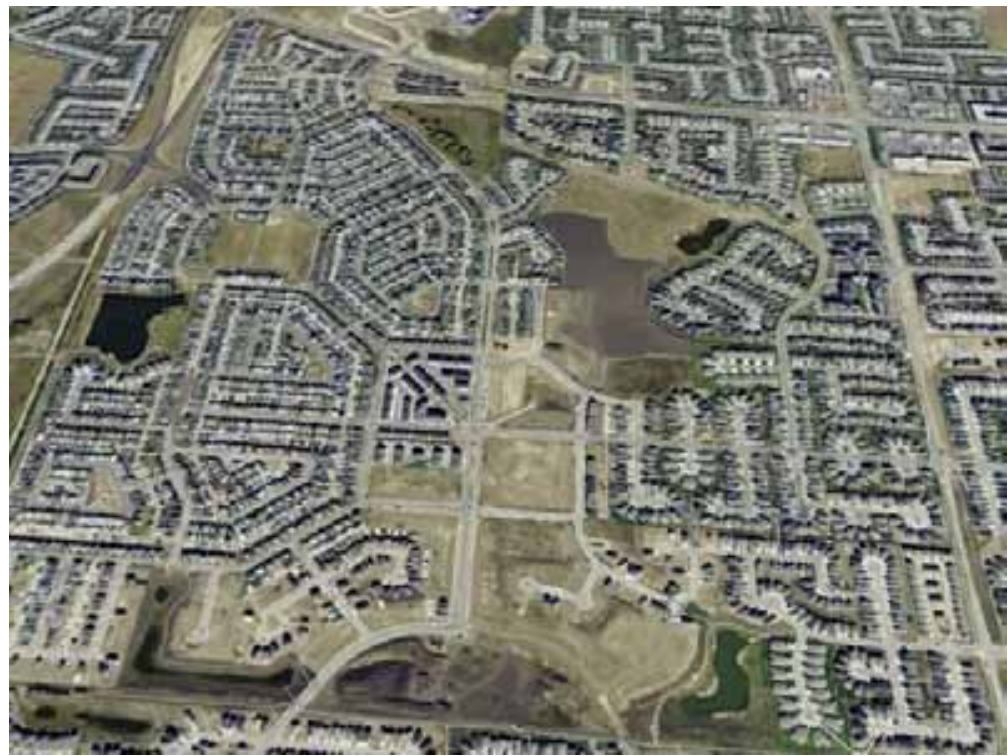

Figure 2. Terwillegar Towne Aerial Image (Source: Google Maps)

\section{Sampling and Questionnaire Development}

Between June and August, 2010, four university students were hired to assist members of the research team in delivering and collecting questionnaires door-to-door. In each neighbourhood, we used clear boundaries (major thoroughfares, natural areas) to delineate a space with 375 households. Questionnaires were only dropped off when a member of the household answered and expressed an interest in participating, and promised to return the questionnaire by mail or to have it picked up by a member of the research team. The overall response rate (491/715) was $69 \%$ (Table 3).

The questionnaire contained five sections. The first asked about frequency of involvement in 37 consumption behaviours, with items de- 
Table 3. Survey Response Rates

\begin{tabular}{lccc}
\hline & Terwillegar Towne & Millcreek & Total \\
\hline Delivered (total) & 375 & 375 & 750 \\
Delivered (accepted) & 358 & 357 & 715 \\
Returned incomplete & 17 & 18 & 35 \\
Not returned & 98 & 93 & 191 \\
Returned & 237 & 254 & 491 \\
Returned, \% & 66 & 71 & 69 \\
\hline
\end{tabular}

rived from the earlier qualitative interviews. The second section asked about the factors important in deciding where to live, as well as the extent to which participants knew their neighbours. The third section asked a series of attitudinal questions related to the economy and about what guided participants in making purchasing decisions. It is likely that there would be some social desirability bias, particularly for the consumption behaviours and purchasing decisions, given that these are self-reported. However, research demonstrates that the tendency to over-report socially desirable behaviors is strongly and positively correlated with educational attainment (Heerwig and McCabe 2009). Since the two neighbourhoods have similar percentages of households holding university degrees (Table 2), whatever social desirability might be present in our sample would be found in both neighbourhood subsamples. The fourth section was about life satisfaction, while the final section asked for sociodemographic information.

\section{Statistical Analyses}

We used the Statistical Package for the Social Sciences (SPSS, version 18) to conduct all analyses. We began with a correlational analysis of the 37 behaviour items (a descriptive analysis of all items is presented in Table 4). These items represent the first four of six domains of practice identified in recent research on sustainable practices (Spaargaren 2011): eating, the home, mobility, clothing and personal care, leisure and travel, and hobbies. We excluded items focusing on "leisure and travel" and "hobbies" since these do not directly address daily household practices.

A series of preliminary analyses reduced the 37 practice measures to a smaller number while ensuring that the four domains of practice continued to be represented. A number of items were highly correlated $(\mathrm{r}=0.600$ or higher, at $\mathrm{p}<.000)$. In each case, we removed all but one of these highly correlated items, ${ }^{3}$ leaving only the item that was most strongly related to the deleted items, resulting in a total of 17 items. Next,

3. Highly correlated items are removed to improve the quality of the cluster analysis results. Unlike a factor analysis, K-means clustering is compromised when items are strongly correlated - the resultant clusters are often so similar that the analysis fails to converge. 
we removed the five items that had over 30 missing responses, leaving us with twelve items all measured on a "Never-Rarely-Sometimes-OftenAlways" scale. These twelve items were entered into the cluster analysis and solutions of 2, 3, 4, 5, 6, and 7 clusters were considered. The validity and reliability of the resulting solutions were assessed by considering face validity and by splitting the data file by neighbourhood to compare consistency of the final clusters across the two neighbourhoods. We profiled the clusters by demographic, spatial, and attitudinal traits using chi-square tests and analyses of variance (ANOVA). Finally, we used a logistic regression to look at the impact of neighbourhood in determining membership in the sustainable consumption cluster, ${ }^{4}$ controlling on attitudes and demographic variables.

Table 4. Behavioural Profile of Consumer Clusters; ANOVA $(n=433)$

\begin{tabular}{|c|c|c|c|c|c|c|}
\hline 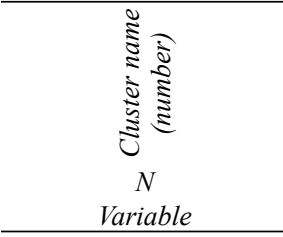 & 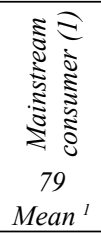 & 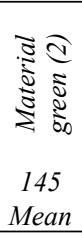 & 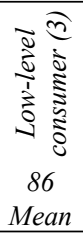 & 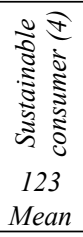 & F Statistic & 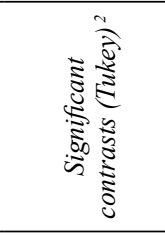 \\
\hline $\begin{array}{l}\text { Leave vehicle at home } \\
\text { to avoid driving }\end{array}$ & 2.19 & 2.56 & 2.99 & 3.51 & $37.043 * * *$ & $1<2<3<4$ \\
\hline $\begin{array}{l}\text { Pay more for something } \\
\text { that lasts a long time }\end{array}$ & 3.28 & 3.83 & 3.46 & 3.84 & $16.014 * *$ & $1,3<2,4$ \\
\hline Buy used goods & 2.35 & 2.49 & 2.75 & 3.09 & $16.313 * *$ & $1<3<4$ \\
\hline Hang laundry to dry & 1.45 & 1.69 & 3.57 & 3.86 & $287.075 * * *$ & $1,2<3<4$ \\
\hline Buy local food & 2.75 & 3.10 & 3.19 & 3.57 & $20.191 * *$ & $1<2,3<4$ \\
\hline $\begin{array}{l}\text { Eat food you or friends/ } \\
\text { family grew }\end{array}$ & 1.82 & 3.00 & 3.07 & 3.50 & $60.625 * * *$ & $1<2,3<4$ \\
\hline $\begin{array}{l}\text { Actively encourage } \\
\text { others to reduce their } \\
\text { consumption }\end{array}$ & 2.01 & 2.66 & 2.75 & 3.47 & $45.821 * * *$ & $1<2,3<4$ \\
\hline $\begin{array}{l}\text { Fix goods rather than } \\
\text { dispose of them }\end{array}$ & 3.39 & 3.46 & 3.95 & 4.20 & $33.225 * * *$ & $1,2<3,4$ \\
\hline $\begin{array}{l}\text { Avoid disposable prod- } \\
\text { ucts }\end{array}$ & 3.43 & 3.45 & 3.95 & 4.16 & $5.818^{*}$ & $1,2<3,4$ \\
\hline Avoid impulse buys & 2.96 & 3.19 & 3.57 & 3.65 & $17.095 * *$ & $1,2<3,4$ \\
\hline Avoid packaging & 3.04 & 3.21 & 3.34 & 3.62 & $13.716^{* *}$ & $1<4$ \\
\hline Avoid bottled water & 3.01 & 3.07 & 4.08 & 4.28 & $43.638 * * *$ & $1,2<3,4$ \\
\hline
\end{tabular}

4. Throughout this paper, we use the term "cluster" to refer to the outcome of a cluster analysis which has as its goal the identification of types of study participants who engage in similar, intercorrelated behaviours, in this case, sustainable consumption behaviours. While we also are interested in the prevalence of such different types of individuals in different neighbourhoods, we are not using the term "clusters" in a spatial sense. 


\section{Results}

The results presented below are structured to address four research questions. A basic descriptive contrast of all behavioural items across the two neighbourhoods is shown in Appendix A.

\section{Are sustainable behaviours clustered among different types of study participants?}

Using a K-means cluster analysis, we selected a four-cluster solution because it yielded maximum between-cluster significance (as measured by ANOVA) for the dataset in its entirety and split by neighbourhood. We use the qualitative work of Niemi and Hubacek (2007), described in the introduction to this paper, to name the resultant four groups. Due to the similarities between those in our study who score lower on all measures (mainstream consumers) and those who score higher on all measures (sustainable consumers), as well as the resemblance between those who adopt weak sustainability practices (material greens) and strong sustainability practices (low-level consumers), we adopt the titles developed by Niemi and Hubacek and apply them to the results of this paper.

Table 4 uses an ANOVA to contrast scores on the behavioural questions for each of the clusters. Cluster 1 (mainstream consumers; $n=79$ ) displays a pattern of low scores across all items while cluster 4 (sustainable consumers; $n=123$ ) has high scores on the same measures. The two central clusters (material greens; $\mathrm{n}=145$ and low-level consumers; $\mathrm{n}=86$ ) can be distinguished by their respective emphasis on altering consumption patterns versus reducing consumption levels. Table 4 also shows the mean scores and standard deviations for each behaviour item by cluster category, as well as which contrasts are statistically significant (reported by cluster number rather than name).

\section{Are sustainable consumers associated with certain individual level demographic and attitudinal measures?}

In Table 5, we present a sociodemographic profile of the four different types of study participants first identified in Table 4. Table 6 presents an attitudinal profile. The direction of analysis is not based on causal assumptions, that is, to state an obvious example, we are not suggesting that membership in the sustainable consumer cluster would lead an individual to have higher education. Instead we are profiling sustainable consumers to show general patterns in their education, age, and other sociodemographic variables. There are few demographic differences between clusters and only slight variability on attitudinal measures. Only 


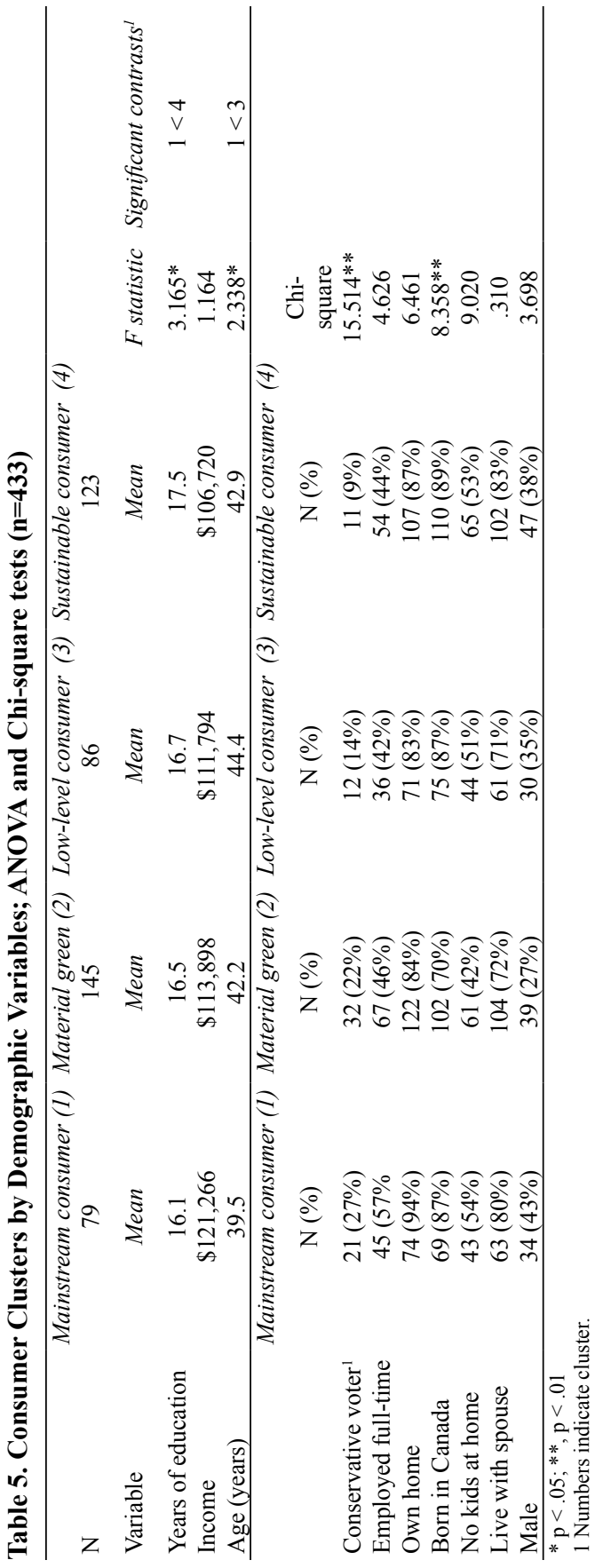


education, age, political affiliation (membership in Conservative Party of Canada), and birthplace differed significantly by cluster. Sustainable consumers have slightly more years of education $(\overline{\mathrm{x}}=17.5)$ than lowlevel consumers $(\overline{\mathrm{X}}=16.7)$, material greens $(\overline{\mathrm{X}}=16.5)$, and mainstream consumers $(\overline{\mathrm{x}}=16.1)$. Mainstream consumers are typically younger $(\overline{\mathrm{X}}=39.5$ years $)$ than low-level consumers $(\overline{\mathrm{X}}=44.4$ years $)$ and material greens are more likely to have been born outside Canada than low-level consumers. Mainstream consumers are more likely to vote for the Conservative Party of Canada than are low-level consumers and sustainable consumers. Income, employment status, gender, and whether one owns or rents their home, lives with a spouse/partner, or has children in the home does not differ significantly across the four clusters, although mainstream consumers have (statistically nonsignificantly) higher incomes than other clusters (Table 5).

In our survey, six attitudinal questions measured approaches to purchasing decisions and nine measured views on the economy. The consumer behaviour clusters are significantly associated with five of the six attitudinal measures about consumption and one of the nine measures of attitudes on the economy. These six measures are displayed in Table 6 . Four of these attitudinal items only differed significantly between mainstream and sustainable consumers. The remaining two items (I am upset when I see things wasted; I feel better when I reduce how much I consume) are significantly different across at least three consumer categories. Compared to members of the other three clusters, sustainable consumers were significantly more likely to agree that "It is important that Canadians consume less." Mainstream consumers were less likely to assign importance to buying durable and high quality goods.

\section{Are sustainable consumers associated with distinct motivations for choosing their neighbourhood?}

As we have noted a number of times earlier in this paper, we acknowledge that the relationship between neighbourhood and social practices is likely bidirectional, that individuals and households might choose one type of neighbourhood over another because of their values and practices, and that neighbourhoods might also shape the practices of those who live in them. To explore the first of these two possibilities, we compared survey respondents' reasons for having chosen where they lived across behaviour clusters. Our analysis included eight different reasons. Responses were measured from 1 to 5, with only the endpoints named $(1=$ not at all important and $5=$ very important). Significant differences across clusters were observed for four motivations for choosing where 
374 C Canadian Journal of Sociology/Cahiers canadiens de sociologie 38(3)2013

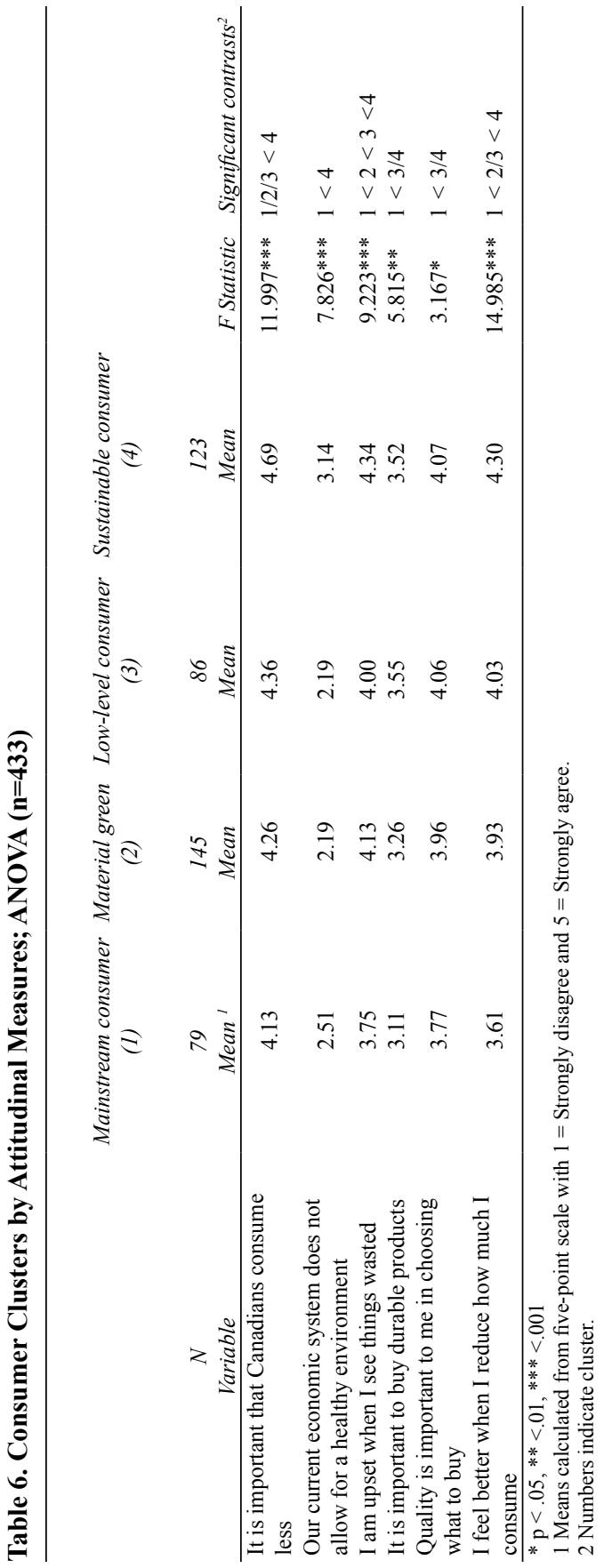


to live. Sustainable consumers ascribed greater importance to living near public transit and less importance to low crime rates and having a large home compared to members of the other clusters, and more importance to living close to work than did mainstream consumers. Mainstream consumers are more likely to want to own a large home and mainstream consumers and material greens are less likely to have wanted to live near parks (Table 7). In short, there are differences across consumer behaviour clusters in factors motivating choices of where to live.

4. Controlling on attitudinal and demographic measures, is neighbourhood (central or suburban) associated with clusters of sustainable consumption practices?

Not surprisingly, given the relationship we observed between motivations for choosing one's neighbourhood and cluster membership (Table 7 ), we find that over $40 \%$ of Millcreek survey participants are classified as sustainable consumers, nearly double the percentage (21\%) among Terwillegar Towne residents (Table 8). The most well-represented behaviour cluster in Terwillegar Towne is the material greens. The percentage of mainstream consumers in Terwillegar Towne is over twice that of Millcreek, and in Millcreek, low-level consumers make up the second largest proportion of residents.

Table 7. Consumer clusters by motivations for neighbourhood choice;

ANOVA (n=433)

\begin{tabular}{|c|c|c|c|c|c|c|}
\hline$N$ & $\begin{array}{c}\text { Mainstream } \\
\text { consumer } \\
\text { (1) } \\
79\end{array}$ & $\begin{array}{c}\text { Material } \\
\text { green } \\
\text { (2) } \\
145\end{array}$ & $\begin{array}{c}\text { Low-level } \\
\text { consumer } \\
\text { (3) } \\
86\end{array}$ & $\begin{array}{c}\text { Sustainable } \\
\text { consumer } \\
\text { (4) } \\
123\end{array}$ & & \\
\hline Variable & Mean ${ }^{l}$ & Mean & Mean & Mean & $F$ Statistic & $\begin{array}{l}\text { Significant } \\
\text { Contrasts }^{2} \\
\end{array}$ \\
\hline Close to work & 3.18 & 3.24 & 3.34 & 3.66 & $3.632 *$ & $1<4$ \\
\hline Close to parks & 3.60 & 3.63 & 4.06 & 4.31 & $14.481^{* * *}$ & $1,2<3,4$ \\
\hline Close to transit & 2.24 & 2.71 & 2.77 & 3.29 & $10.981 * * *$ & $1<2,3<4$ \\
\hline Large home & 2.76 & 2.39 & 2.21 & 1.75 & $17.605^{* * *}$ & $4<3,2<1$ \\
\hline Low crime rate & 3.93 & 4.15 & 3.90 & 3.68 & $4.672 * *$ & $4<3,1<2$ \\
\hline
\end{tabular}

Table 8. Consumer Clusters by Neighbourhood; Chi-square Tests

\begin{tabular}{llllll}
\hline \multicolumn{1}{c}{ Variable } & $\begin{array}{c}\text { Mainstream } \\
\text { consumer }\end{array}$ & $\begin{array}{c}\text { Material } \\
\text { green }\end{array}$ & $\begin{array}{l}\text { Low-level } \\
\text { consumer }\end{array}$ & $\begin{array}{c}\text { Sustainable } \\
\text { consumer }\end{array}$ & Chi-square \\
\hline Neighbourhood & & & & & \\
Terwillegar Towne & $25.9 \%$ & $40.1 \%$ & $13.2 \%$ & $20.8 \%$ & $41.559 * * *$ \\
Millcreek & $12.5 \%$ & $22.8 \%$ & $24.6 \%$ & $40.2 \%$ & $41.559 * * *$ \\
$N$ & 79 & 145 & 86 & 123 & \\
\hline$* * * \mathrm{p}<.000$ & & & & &
\end{tabular}


While the relationship between neighbourhood and sustainable consumption practices (Table 8 ) is strong and statistically significant, it remains possible that age, income, education, and various attitudes associated with membership in the four different categories of consumption practices (see Tables 5 and 6) might be responsible for the adoption of different sets of behaviours, more than the neighbourhood itself. To explore this possibility we use a binary logistic regression analysis to examine the association between neighbourhood and membership, controlling for variables that were found earlier to be significantly related (e.g., age, place of birth, years of education, and attitudes). In Table 10, membership in the sustainable consumer cluster is a binary dependent variable (sustainable consumers were assigned a value of 1 ; members of the three other behaviour clusters were given a score of 0 ). Education was recoded as a binary variable $(1=$ at least an undergraduate degree, $0=$ all others $)$, as was immigrant status $(1=$ born in Canada; $0=$ all others). Age is measured in years. The attitudinal items presented in Table 6 were combined into an additive scale titled "environmental attitude" (Cronbach's Alpha $=0.633$ ), with higher scores indicating more pro-environmental attitudes (see Table 7). Neighbourhood is coded as "1" for Millcreek and "0" for Terwillegar Towne.

Table 9 shows that pro-environmental attitudes and neighbourhood of residence had significant partial effects on behaviour cluster membership (the Hosmer and Lemeshow test of goodness-of-fit suggests that the model is a good fit to the data). The odds ratio for neighbourhood indicates that, when holding all other variables constant, a resident of Millcreek is nearly twice as likely as a resident of Terwillegar Towne to adopt those practices indicative of membership in the sustainable consumer cluster. Inverting the odds ratio for attitude reveals that for each one-point increase on the 7-35 attitudinal scale, likelihood of being a sustainable consumer increases by a factor of 1.2. Although not statistically significant, older people are less likely to be sustainable consumers, while Canadian-born respondents are more likely to be sustainable consumers. Future research with a larger sample size may reveal significant differences for these and other variables.

\section{Discussion}

In our efforts to understand how pro-environmental practices differ across two neighbourhoods, we found four distinct subgroups of respondents. These groups differ in the number of sustainable practices adopted (particularly between mainstream and sustainable consumers) and the type of practices adopted; sustainable and low-level consum- 
Table 9. Binary logistic Regression Analysis of Membership in Sustainable Consumption Cluster $(n=433)$

\begin{tabular}{lrcccc}
\hline & $\beta$ & se $\beta$ & Wald's Chi-square & $p$ & $e \beta$ (odds ratio) \\
\hline Constant & -8.011 & 1.225 & 38.167 & 0.000 & - \\
Environmental attitude & 0.256 & 0.041 & 35.410 & $\mathbf{0 . 0 0 0}$ & 1.292 \\
Age & -0.008 & 0.011 & 0.511 & 0.475 & 0.992 \\
Born in Canada & 0.167 & 0.312 & 0.285 & 0.593 & 1.181 \\
University education & 0.167 & 0.252 & 0.550 & 0.458 & 1.206 \\
Conservative voter & -0.461 & 0.371 & 1.543 & 0.214 & 0.631 \\
Neighbourhood & 0.612 & 0.263 & 5.432 & $\mathbf{0 . 0 2 0}$ & 1.845 \\
Test & & & Chi-square & $d f$ & $P$ \\
Goodness of fit (Hosmer and & & 6.645 & 8 & 0.614 \\
Lemeshow) & & & &
\end{tabular}

Cox and Snell $\mathrm{R}^{2}=0.156$, Nagelkerke $\mathrm{R}^{2}\left(\right.$ Max rescaled $\left.\mathrm{R}^{2}\right)=0.219$.

ers are more likely to adopt time-intensive routines and material greens are more likely to make cost-intensive choices. Mainstream consumers are unlikely to hang their laundry or grow their own food but will pay more for something that lasts a long time and fix things rather than dispose of them. Material greens likely will not buy used goods or leave their vehicle at home to avoid driving, but they would buy local food if available (many interview and survey participants in our mixed methods study mentioned the absence of farmers' markets in Terwillegar Towne as a barrier to buying local food). Sustainable consumers participate in a wide range of "green" practices, such as fixing goods as opposed to buying new and avoiding the purchase of disposable products.

Additionally, we found that sustainable consumers have stronger pro-environmental attitudes, a finding also observed by Bamberg (2003) and Dunlap et al. (2000). Most importantly, our analyses demonstrate that residents of different neighbourhoods demonstrate unique patterns of consumption behaviour. The urban literature reminds us that there are several explanations for this finding. Suburbs and central city communities may impose different types of consumer practices (a deterministic interpretation). Alternatively, different types of communities might attract different kinds of residents (a selection bias) and their local cultures might influence their behaviours (a compositional interpretation). While we cannot determine the causal direction, and actually believe that both processes are at work in a dialectical manner, our primary goal is to simply draw attention to the strong relationship between neighbourhood and sustainable consumption behaviours (or their absence). ${ }^{5}$ As Logan and

5. Selection bias is likely at work in our study, perhaps even constituting an additional neighbourhood effect, as Sampson (2012) argued. However, as one anonymous reviewer noted, it probably has a conservative effect, reducing the variation in consuming practices due to the likelihood that most nonrespondents would be classified as "mainstream" consumers. 
Molotch (1987) might have argued, neighbourhoods, shaped by market forces and external actors as well as by residents (the latter perhaps attracted there because they were predisposed to what the neighbourhood offered), can in turn influence the "daily rounds," including sustainable consumption patterns, of their residents.

The typical suburban community, permitted by municipal politicians, built by profit-seeking developers at the edge of a city, and populated by residents often eager to live there, offers little in the way of public infrastructure, points of interest, and retail opportunities (Grant and Bohdenow 2008). This results in structural and cultural processes that significantly influence sustainable consumption practices, in particular, those related to sustainable transportation (Kennedy et al. 2013). Without amenities nearby, and with workplaces far away, suburban residents are required to spend much more time driving than are central city residents. As Harvey (1989:39) observed, suburbanization is a "total restructuring of space to mobilize demand so as to make the consumption of the products of the car, oil, rubber, and construction industries a necessity rather than a luxury." Ironically, data from the interview phase of our study suggested that, for some environmentally concerned suburban residents, discourse and rhetoric alluding to a new urbanism (community-based suburbs with access to shops and services) had lured them to their current homes with promises of social networks, walkability, and less driving for shopping, even though little of the community infrastructure promised by developers was built until over a decade later.

Even so, the compositionalist perspective on neighbourhood effects reminds us that residential interactions can influence sustainable consumption practices, and such interactions could occur in less likely neighbourhoods, including the suburbs. However, once an individual has chosen where to live, their possibilities for adopting patterns of different (from the culture of the community) behaviours are considerably reduced (Florida 2009; Zegras 2010). As discussed elsewhere (Horton 2006; Kennedy 2011), social networks based on sustainable practices form more readily when individuals are able to run into one another at local points of interest, and neighbourhoods are a particularly important location for the formation and functioning of social networks (Guest 2006; Logan and Molotch 1987). The relevance of such networks for sustainable consumption practices lies in the observation that visibility through social networks is necessary for cultural shifts to take hold (Christakis and Fowler 2009; Starr 2009).

Future research in this area should focus on identifying the social, economic, and political processes that mediate the causal pathways between neighbourhood and sustainable consumption practices. Longi- 
tudinal data would be particularly useful. So too would be a sampling of a large number of neighbourhoods with different physical and sociodemographic compositions. Comparison of neighbourhoods with different social class compositions, for example, might reveal how the culture of middle-class North American neighbourhoods, which are more likely to emphasize pro-environmental values and behaviour (Grigsby 2004; Nevarez 2011), manifest (or not) in different sustainable consumption practices. We conclude by arguing many sustainable activities are more difficult to incorporate into daily routine when residing in the suburban neighbourhood. While suburban residents may feel strongly that they should consume less, their geographic location appears to significantly constrain their ability to meaningfully reduce their own consumption.

\section{REFERENCES}

Bamberg, Sebastian. 2003. How does environmental concern influence specific environmentally related behaviors? A new answer to an old question. Journal of Environmental Psychology 23(1):21-32.

Baxandall, Rosalyn F. and Elizabeth Ewen. 2000. Picture Windows: How the Suburbs Happened. New York: Basic Books.

Bell, Michael M. 2004. An Invitation to Environmental Sociology. Thousand Oaks, CA: Pine Forge Press.

Berman, Tzeborah and Mark Leiren-Young. 2011. This Crazy Time: Living our Environmental Challenge. Toronto: Random House.

Borer, Michael I. 2006. The location of culture: The urban culturalist perspective. City \& Community 5(2):173-197.

Brewster, Karen L., John O.G. Billy, and William R. Grady. 1993. Social context and adolescent behavior: The impact of community on the transition to sexual activity. Social Forces 71:713-740.

Capek, Sylvia M. 2010. Foregrounding nature: An invitation to think about shifting nature-city boundaries. City \& Community 9(2):208-224.

Christakis, Nicholas A. and James H. Fowler. 2009. Connected: The Surprising Power of Our Social Networks and How They Shape Our Lives. New York: Little \& Brown.

De Graaf, John, David Wann, and Thomas H. Naylor. 2001. Affluenza: The AllConsuming Epidemic. San Francisco, CA: Berrett-Koehler.

Dunlap, Riley E. 2002. An enduring concern: Light stays green for environmental protection. Public Perspective 13:Sept/Oct, 10-14.

Fischer, Clive S. 1976. The Urban Experience. New York: Harcourt Brace Jovanovich. 
Florida, Richard. 2009. Who's Your City? How the Creative Economy is Making Where You Live the Most Important Decision of Your Life. Toronto: Vintage Canada.

Fosket, Jennifer and Laura Mamo. 2009. Living Green: Communities that Sustain. Gabriola Island, BC: New Society Publishers.

Friedman, Thomas L. 2005. The World is Flat: A Brief History of the Twentieth Century. New York: Farrar, Strauss, and Giroux.

Gans, Herbert J. 1962. City planning and urban realities. Commentary 33(2):170 175.

1963. Effects of the move from city to suburb. In L.J. Duhl, ed., The Urban Condition. New York: Basic Books.

Gieryn, Thomas. 2000. A space for place in sociology. Annual Review of Sociology 26:463-496.

Giddens, Anthony. 1991. Modernity and Self-Identity: Self and Society in the Late Modern Age. Stanford, CA: Stanford University Press.

Grant, Jillian L. and Stephanie Bohdenow. 2008. New urbanism developments in Canada: A survey. Journal of Urbanism 1(22):109-127.

Grant, Jillian. 2002. From "sugar cookies" to "gingerbread men": Conformity in suburban design. Planners Network Bulletin 151:Spring, 10-13.

Grigsby, Mary. 2004. Buying Time and Getting By. New York: State University of New York Press.

Guest, Avery M., Jane K. Cover, Ross L. Matsueda, and Charis E. Kubrin. 2006. Neighborhood context and neighboring ties. City \& Community 5(4):363-382.

Harvey, David. 1989. The Urban Experience. Baltimore, MD: Johns Hopkins University Press.

Heerwig, Jennifer A. and Brian J. McCabe. 2009. Education and social desirability bias: The case of a black presidential candidate. Social Science Quarterly 90:674-86.

Hodson, Mike and Simon Marvin. 2010. Can cities shape socio-technical transitions and how would we know if they were? Research Policy 39(4):477485.

Horton, Dave. 2006. Demonstrating ecological citizenship? A study of everyday life among green activists. In A. Dobson and D. Bell, eds., Environmental Citizenship. Cambridge, MA: The MIT Press.

Jacobs, Jane. 1961. The Death and Life of Great American Cities. New York: Random House.

Johnston, Josée, Michelle Szabo, and Andrea Rodney. 2011. Good food, good people: Understanding the cultural repertoire of ethical eating. Journal of Consumer Culture 11(3):293-318.

Kawachi, Ichiro and Lisa F. Berkman, eds. 2003. Neighborhoods and Health. New York: Oxford University Press. 
Kennedy, Emily H. 2011. Ecological citizenship and the social network: Observing a virtuous circle in action. Environmental Politics 20(6):843-860.

Kennedy, Emily H., Harvey Krahn, and Naomi T. Krogman. 2013. Chapter 12: Taking social practice theory on the road: A mixed methods case study of sustainable transportation. Pp. 252-276 in H. Brown, M. Cohen, and P. Vergragt, eds., Ecological Macroeconomics, Social Practices, and the New Economics: Toward a Synthesis. Northampton, MA: Edward Elgar Publishing.

Logan, John and Harvey Molotch. 1987. Urban Fortunes: The Political Economy of Place. Berkeley, CA: University of California Press.

Lorr, Michael J. 2012. Defining urban sustainability in the context of North American cities. Nature and Culture 7(1):16-30.

Manheim, Ernest. 1960. Theoretical prospects of urban sociology in an urbanized society. American Journal of Sociology 66(3):226-229.

May, Tim, Beth Perry, Patrick Le Gales, Saskia Sassen, and Mike Savage. 2005. The future of urban sociology. Sociology 39(2):343-370.

Molotch, Harvey L., William E. Freudenberg, and Krista E. Paulsen. 2000. History repeats itself, but how? City character, urban tradition, and the accomplishment of place. American Sociological Review 65:Dec, 791-823.

Morenoff, Jeffrey D. and Robert J. Sampson. 1997. Violent crime and the spatial dynamics of neighborhood transition: Chicago, 1970-1990. Social Forces 76:31-64.

Nevarez, Leonard. 2011. Pursuing Quality of Life: From the Affluent Society to the Consumer Society. New York: Taylor and Francis.

Niemi, Carita J. and Klaus Hubacek. 2007. The role of social capital in sustainable consumption. The International Journal of Interdisciplinary Social Sciences 1(6):1-10.

Ross, Catherine E. 2000. Walking, exercising, and smoking: Does neighborhood matter? Social Science \& Medicine 51:265-274.

Rudel, Thomas K. 2009. How do people transform landscapes? A sociological perspective on suburban sprawl and tropical deforestation. American Journal of Sociology 115(1):129-154.

Sampson, Robert J. 2012. Great American City: Chicago and the Enduring Neighborhood Effect. Chicago, IL: University of Chicago Press.

Seyfang, Gillian. 2009. The New Economics of Sustainable Consumption: The Seeds of Change. New York: Palgrave Macmillan.

Spaargaren, Gert. 2011. Theories of practices: Agency, technology, and culture. Exploring the relevance of practice theories for the governance of sustainable consumption practices in the new world-order. Global Environmental Change 21(3):813-822. 
Starr, Martha A. 2009. The social economic of ethical consumption: Theoretical considerations and empirical evidence. Journal of Socio-Economics 38(6):916-925.

Statistics Canada. 2006. Survey of household spending. The Daily. 12 December 2006. Available at http://www.statcan.ca/Daily/English/061212/ d061212b.html (accessed 8 November 2009).

Szasz, Andrew. 2007. Shopping Our Way to Safety: How We Changed from Protecting the Environment to Protecting Ourselves. Minneapolis, MN: University of Minnesota Press.

Turcotte, Martin. 2008a. The difference between city and suburb: How can we measure it? Canadian Social Trends, 85. Catalogue no. 11-008-XIE, Ottawa: Minister of Industry. 2008b. Life in metropolitan areas: Dependence on cars in urban neighborhoods. Canadian Social Trends. Statistics Canada. Catalogue No. 11008 .

Wirth, Louis. 1938. Urbanism as a way of life. American Journal of Sociology 44(1):1-24.

Zegras, Christopher. 2010. The built environment and motor vehicle ownership and use: Evidence from Santiago de Chile. Urban Studies 47(8):17931817.

Emily Huddart Kennedy is an assistant professor in the Department of Resource Economics and Environmental Sociology at the University of Alberta. Her research areas are in sustainable consumption, environmental citizenship, and mixed methods.

Harvey Krahn is Professor and Chair in the Department of Sociology at the University of Alberta. His research interests are in social inequality, education and work, political sociology, sustainable consumption, and immigration.

harvey.krahn@ualberta.ca

Naomi Krogman is a Professor in the Department of Resource Economics and Environmental Sociology at the University of Alberta. Her research areas are in sustainable consumption, environmental policy implementation, social impacts of resource development, and gender and land-related decision-making in the developing world. She is currently the Academic Director of the Office of Sustainability and working on the area of sustainability sciences and the role of sustainability curriculum and research in higher education.

naomi.krogman@ualberta.ca 


\section{Appendix A}

Table 10. Descriptive Analysis of all Behaviour Items, by Neighbourhood (\%)

\begin{tabular}{|c|c|c|c|c|c|c|}
\hline \multirow[t]{2}{*}{ Item } & \multicolumn{2}{|c|}{$\begin{array}{c}\text { Never/ } \\
\text { Rarely (\%) }\end{array}$} & \multicolumn{2}{|c|}{$\begin{array}{l}\text { Sometimes } \\
(\%)\end{array}$} & \multicolumn{2}{|c|}{$\begin{array}{c}\text { Often/ } \\
\text { Always (\%) }\end{array}$} \\
\hline & $T T^{*}$ & $M C$ & $T T$ & $M C$ & $T T$ & $M C$ \\
\hline Leave vehicle at home to avoid driving & 54.3 & 16.7 & 34.8 & 38.5 & 9.9 & 44.8 \\
\hline Bike to avoid driving & 72.5 & 9.5 & 41.6 & 35.7 & 15.9 & 54.8 \\
\hline Walk to avoid driving & 68.7 & 44.2 & 22.3 & 24.7 & 9.0 & 31.1 \\
\hline Use transit to avoid driving & 71.9 & 46.9 & 14.0 & 25.4 & 14.0 & 27.8 \\
\hline Pay more for something that lasts a long time & 6.5 & 4.8 & 35.2 & 34.3 & 58.3 & 60.9 \\
\hline Buy used goods & 46.1 & 31.9 & 40.6 & 37.8 & 13.3 & 30.3 \\
\hline Reuse goods & 4.3 & 2.4 & 17.4 & 11.4 & 78.3 & 86.2 \\
\hline Compost waste & 76.2 & 48.5 & 9.7 & 18.6 & 14.1 & 42.8 \\
\hline Reduce temperature of home to save energy & 6.0 & 8.4 & 19.9 & 16.0 & 74.2 & 75.6 \\
\hline Turn off computer when not in use & 18.4 & 15.4 & 23.1 & 22.0 & 58.6 & 62.6 \\
\hline Hang laundry to dry & 35.7 & 36.9 & 30.9 & 24.2 & 33.5 & 38.9 \\
\hline Reduce temperature of water heater & 52.8 & 49.6 & 16.7 & 14.9 & 30.4 & 35.5 \\
\hline Buy local food & 23.2 & 10.9 & 52.8 & 42.7 & 22.3 & 46.3 \\
\hline or friends / family grew & 37.1 & 27.1 & 39.2 & 35.9 & 23.7 & 37.1 \\
\hline cratch & 6.4 & 2.4 & 11.5 & 10.4 & 82.0 & 87.2 \\
\hline Avoid use of herbicides on lawn & 5.9 & 5.0 & 20.8 & 7.5 & 73.3 & 87.5 \\
\hline Use a rain barrel & 77.7 & 63.5 & 8.9 & 9.6 & 13.4 & 26.9 \\
\hline$n$ advocacy group & 72.8 & 60.1 & 19.6 & 22.7 & 7.6 & 17.2 \\
\hline Partic & 43.6 & 36.1 & 37.7 & 32.9 & 18.7 & 31.0 \\
\hline nity garden & 90.4 & 93.1 & 3.9 & 0.8 & 5.6 & 6.2 \\
\hline Help nei & 25.8 & 23.9 & 38.1 & 38.6 & 36.0 & 37.5 \\
\hline Accept unpaid help fror & 37.3 & 37.4 & 38.1 & 37.5 & 24.5 & 25.1 \\
\hline $\begin{array}{l}\text { Talk about environmental issues in your } \\
\text { household }\end{array}$ & 12.8 & 7.0 & 44.9 & 35.1 & 42.3 & 57.8 \\
\hline $\begin{array}{l}\text { Talk to those outside your household about } \\
\text { environmental issues }\end{array}$ & 14.9 & 7.2 & 49.8 & 44.0 & 35.3 & 48.8 \\
\hline $\begin{array}{l}\text { Behave in ways that shows others how to } \\
\text { reduce consumption }\end{array}$ & 16.8 & 15.5 & 47.4 & 38.6 & 35.8 & 45.9 \\
\hline Encourage others to reduce consumption & 37.8 & 35.3 & 40.3 & 34.9 & 21.9 & 29.8 \\
\hline fun & 35.3 & 50.0 & 41.1 & 29.8 & 23.3 & 20.3 \\
\hline ou could fix & 5.0 & 4.0 & 41.4 & 24.9 & 53.6 & 71.2 \\
\hline disposable products & 6.3 & 3.6 & 38.1 & 37.2 & 55.5 & 59.2 \\
\hline Avoid impulse buys & 14.9 & 10.0 & 47.9 & 45.0 & 37.3 & 45.1 \\
\hline $\begin{array}{l}\text { Avoid buying products with a lot of pack- } \\
\text { aging }\end{array}$ & 13.2 & 9.5 & 56.4 & 46.9 & 30.4 & 40.9 \\
\hline \multirow[t]{3}{*}{ Avoid buying bottled water } & 21.6 & 14.0 & 32.1 & 17.6 & 46.4 & 68.4 \\
\hline & \multicolumn{2}{|c|}{ Average... } & \multicolumn{2}{|c|}{ Yes } & \multicolumn{2}{|c|}{ No } \\
\hline & \multicolumn{2}{|c|}{$T T$} & \multicolumn{2}{|c|}{$T T$} & \multicolumn{2}{|c|}{$T T \quad M$} \\
\hline Number of cars & 1.97 & & - & & - & - \\
\hline Of those, how many are fuel-efficient & 0.91 & & - & & - & - \\
\hline $\begin{array}{l}\text { Number of flights in } 2009 \text { (combined for } \\
\text { household) }\end{array}$ & 15.03 & & & & - & - \\
\hline $\begin{array}{l}\text { Number of cans of garbage disposed of each } \\
\text { week }\end{array}$ & 1.83 & & & & - & \\
\hline $\begin{array}{l}\text { Does your household have a front-loading } \\
\text { washer? }\end{array}$ & - & & 59.7 & & 40.3 & 53.1 \\
\hline
\end{tabular}


